\title{
The long-term freshening and nutrient increases in summer surface water in the northern East China Sea in relation to Changjiang discharge variation
}

\author{
Eko Siswanto, ${ }^{1,2}$ Hideaki Nakata, ${ }^{3}$ Yuji Matsuoka, ${ }^{4}$ Katsuhisa Tanaka, ${ }^{5}$ Yoko Kiyomoto, ${ }^{6}$ \\ Kazumaro Okamura, ${ }^{6}$ Jianrong Zhu, ${ }^{7}$ and Joji Ishizaka ${ }^{3}$ \\ Received 15 March 2008; revised 18 August 2008; accepted 25 August 2008; published 30 October 2008.
}

[1] Using historical in situ data sets, we investigated long-term variations in summer surface salinity and dissolved inorganic nitrogen concentration (DIN) in the northern East China Sea (ECS). From 1950 to 2002, there were interannual and decadal variations in sea surface salinity, as well as a long-term decrease. Along with the Changjiang discharge, wind fields and surface circulations appeared to play roles in determining the interannual salinity variation. Although we attributed the long-term decrease in surface salinity to a long-term increase in the Changjiang discharge, the high salinity between 1978 and 1988 appeared to be associated with an increase in the Kuroshio Current transport. The increase in DIN from 1971 to 2001 appeared to be caused by a combination of changes in Changjiang discharge and an increase in nitrogen fertilizer use in China. The long-term increase in DIN modified the nutrient composition, implying that biological production in the northern ECS changed from a DIN-limiting to a phosphorous-limiting. We should pay attention to changes in the northern ECS ecosystem in future decades because the volume of the Changjiang discharge, as well as its physical and chemical properties, may change dramatically because of the continuous anthropogenic perturbations and climate change.

Citation: Siswanto, E., H. Nakata, Y. Matsuoka, K. Tanaka, Y. Kiyomoto, K. Okamura, J. Zhu, and J. Ishizaka (2008), The long-term freshening and nutrient increases in summer surface water in the northern East China Sea in relation to Changjiang discharge variation, J. Geophys. Res., 113, C10030, doi:10.1029/2008JC004812.

\section{Introduction}

[2] The Changiiang (Yangtze River) is the main freshwater discharge source, and one of the main nutrient sources, for the East China Sea (ECS). The river has been undergoing long-term ecosystem modifications because of anthropogenic activities, such as chemical fertilizer use, dam construction, and land use modifications. Eutrophication and more frequent red tide breakouts in Chinese coastal waters in the last decade are some of the environmental problems caused by these long-term anthropogenic activities [e.g., Gao and Song, 2005; Li et al., 2007; Wang, 2006]. Giant jellyfish (Nemopilema nomurai) population explo-

\footnotetext{
${ }^{1}$ Hydrospheric Atmospheric Research Center, Nagoya University, Nagoya, Japan.

${ }^{2}$ Agency for the Assessment and Application of Technology, Jakarta, Indonesia.

${ }^{3}$ Faculty of Fisheries, Nagasaki University, Nagasaki, Japan.

${ }^{4}$ Nagasaki Food Hygiene Association, Nagasaki, Japan.

${ }^{5}$ Japan International Research Center for Agricultural Sciences, Tsukuba, Japan.

${ }^{6}$ East China Sea Fisheries Oceanography Division, Seikai National Fisheries Research Institute, Nagasaki, Japan.

${ }^{7}$ State Key Laboratory of Estuarine and Coastal Research, East China Normal University, Shanghai, China.

Copyright 2008 by the American Geophysical Union. 0148-0227/08/2008JC004812
}

sions in the ECS in recent years also suggest that marine ecosystem changes may be occurring [see Kawahara et al., 2006].

[3] Nutrient concentration in the Changjiang estuary and sediment loaded into the ECS have been intensively investigated as proxies for long-term environmental changes, as they seem likely to be directly affected by anthropogenic activities. Xu et al. [2006] found that the sediment flux from the Changjiang has decreased since 1950, independently of the long-term Changjiang discharge variation. Previous studies have investigated the long-term variation of nutrient concentration and composition [e.g., Chai et al., 2006; Li et al., 2007], but they mostly covered the region around the Changjiang, its estuary, and its adjacent waters. The longterm nutrient variations in regions further offshore have not been documented.

[4] However changes in the Changjiang basin are not only caused by human activities. Climatic changes, such as changes in precipitation over the Changjiang valley, have also played a role. It has been observed that summer precipitation over the Changjiang valley (east of $107^{\circ} \mathrm{E}$ ) shifted in the late 1970s [Gong and Ho, 2002]. The climate of the Changjiang source region in the Tibetan Plateau of western China (west of $105^{\circ} \mathrm{E}$ ) has also warmed, causing increases in glacier retreat and runoff there [Ding et al., 2006]. Such long-term increases in precipitation and melt- 
water from glaciers might lead to long-term variations in the Changjiang discharge and hence in sea surface salinity in the ECS.

[5] Changes in the Changjiang discharge and sea surface salinity in the ECS are expected to influence the marine ecosystem of the Japan Sea. Diversion of freshwater from the Changjiang could induce frequent bottom water formation in the Japan Sea through changes in the surface salinity [Nof, 2001]. Yanagi [2002] further suggested that changes in salinity in the ECS could cause serious changes in nutrient conditions in the upper $200 \mathrm{~m}$ of the Japan Sea. The northern ECS is thus an important checkpoint for investigating the long-term salinity and nutrient variations influenced by Changjiang discharge, as the Changjiang diluted water $(\mathrm{CDW})$ flows through this region to the Tsushima Straits, after which it enters the Japan Sea [e.g., Chang and Isobe, 2003; Senjyu et al., 2006]. It is therefore crucial to investigate the long-term changes in sea surface salinity and nutrients in the northern ECS, particularly those related to the Changjiang discharge variation.

[6] We investigated the long-term variations in sea surface salinity and nutrients from 1950 to 2002, and 1971 to 2001, respectively. The long-term variation in Changjiang discharge from 1950 to 2002 was also examined. We chose 1950 as the starting year of analysis because a complete time-series of the Changjiang discharge has been available since then. We chose 2002 as the final year because we wanted to know the long-term variations of sea surface salinity and Changjiang discharge before the freshwater impoundment in June 2003 by the world's largest hydroelectric dam, the Three Gorges Dam (TGD), situated in the middle reaches of the Changjiang.

[7] This study provides basic information on present environmental conditions in the northern ECS and thus will be an important starting point for assessing future changes in the marine ecosystem in the ECS and its connected seas. Our aim was to investigate long-term variations in sea surface salinity and nutrients, and their relationship with the variation of the Changjiang discharge. However the path of the Changjiang plume, and hence the offshore extension of the low-salinity water mass on the shelf region, varies dramatically because of complicated surface circulations that are influenced by the Taiwan Warm Current, the Kuroshio Current, and wind-driven Ekman transport [e.g., Chang and Isobe, 2003]. Therefore it is possible that variation in the sea surface salinity is not only determined by the Changjiang discharge, but also by these multiple factors. We discuss the most likely mechanisms behind the observed variations in surface salinity and nutrients. We also discuss the relevance of our work to some of the marine environmental problems experienced recently.

\section{Data Sources}

[8] We acquired sea surface salinity data in the northern ECS from 1950 to 2002 from the Japan Oceanographic Data Center. Dissolved inorganic nitrogen concentration (DIN: Nitrate + Nitrite, $\mu \mathrm{M})$ data from 1971 to 2001 were obtained from the Seikai National Fisheries Research Institute of Japan and the Japan Meteorological Agency.

[9] We were also interested in assessing the long-term excess DIN as an indicator of the changes in nutrient composition in the northern ECS. The excess DIN was computed following the method of Wong et al. [1998] using the equation

$$
\text { Excess DIN }=\mathrm{DIN}-14.5 \mathrm{PO}_{4}-\mathrm{P},
$$

where $\mathrm{PO}_{4}-\mathrm{P}$ is the phosphate concentration $(\mu \mathrm{M})$, which was obtained from the Seikai National Fisheries Research Institute of Japan and the Japan Meteorological Agency. Excess DIN is the DIN in excess of that which can be used by marine phytoplankton given the observed $\mathrm{PO}_{4}-\mathrm{P}$ levels. We computed it from 1981 onward because there were no $\mathrm{PO}_{4}-\mathrm{P}$ data earlier.

[10] The Changjiang discharge data measured at the Datong hydrological gauging station in the downstream Changjiang region ( $\sim 680 \mathrm{~km}$ from the Changjiang mouth) from 1950 to 2002 were used. Discharge data from 1950 to 1988 and from 1998-2002 were obtained from the Monthly Discharge Data for World Rivers [Bodo, 2001] and the Ministry of Water Resources of the Peoples' Republic of China [http://www.net.cn and http://www. hydroinfo.gov.cn], respectively.

[11] To investigate the probable influence of the wind field on sea surface salinity variation, wind vector components ( $\mathrm{u}$ and $\mathrm{v}, \mathrm{m} \mathrm{s}^{-1}$ ) from the International Comprehensive Ocean-Atmosphere Data Set (ICOADS) with 2-degree spatial resolution were acquired from the website of the Royal Netherlands Meteorological Institute (KNMI, http:// climexp.knmi.nl). These wind component data were used to derive the wind magnitude and direction.

\section{Period and Region of the Study}

[12] About $40 \%$ of the annual Changjiang discharge occurred from June to August [Yang et al., 1983]. We computed the monthly mean Changjiang discharge over 53 yr from 1950 to 2002 and found that by average, July was the month with the highest Changjiang discharge (Figure 1a), agrees with the results of Yang et al. [1983] and Senjyu et al. [2006]. Such a high discharge inevitably has a large impact on the offshore ecosystems, as more terrestrial materials and freshwater are discharged into the ECS. The July discharge also covaried with the annual mean, annual maximum, and summer mean (from June to August) discharges (Figure 1b), suggesting that July discharge could be used as an indicator of the summer Changjiang discharge. In this study, we therefore related only the July Changjiang discharge (hereafter referred to as the summer Changjiang discharge) to the summer sea surface salinity and nutrient variations in the northern ECS.

[13] To show the spatial and temporal variations in summer sea surface salinity, we used all summer sea surface salinity data measured in a region from $31^{\circ}$ to $32^{\circ} \mathrm{N}$ and $122^{\circ} 15^{\prime}$ to $130^{\circ} \mathrm{E}$ (Figure 2) from 1950 to 2002 . However, to show the long-term variation of summer sea surface salinity, our analysis emphasized the region from $31^{\circ}$ to $32^{\circ} \mathrm{N}$ and $124^{\circ} 30^{\prime}$ to $125^{\circ} 30^{\prime} \mathrm{E}$ and the period from 1951 to 2001 because of data availability. The long-term variation in summer DIN was derived from all summer data west of $125^{\circ} 30^{\prime} \mathrm{E}$ (Figure 2). We defined the summer salinity and DIN as the mean values averaged from July to September. Because the ICOADS wind component data had 2-degree 


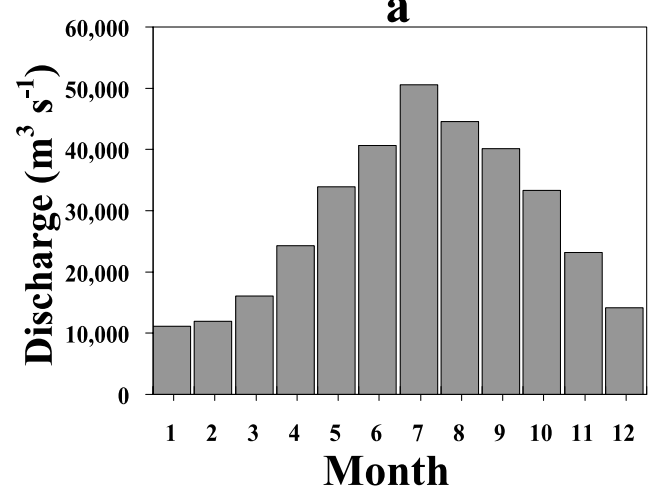

b

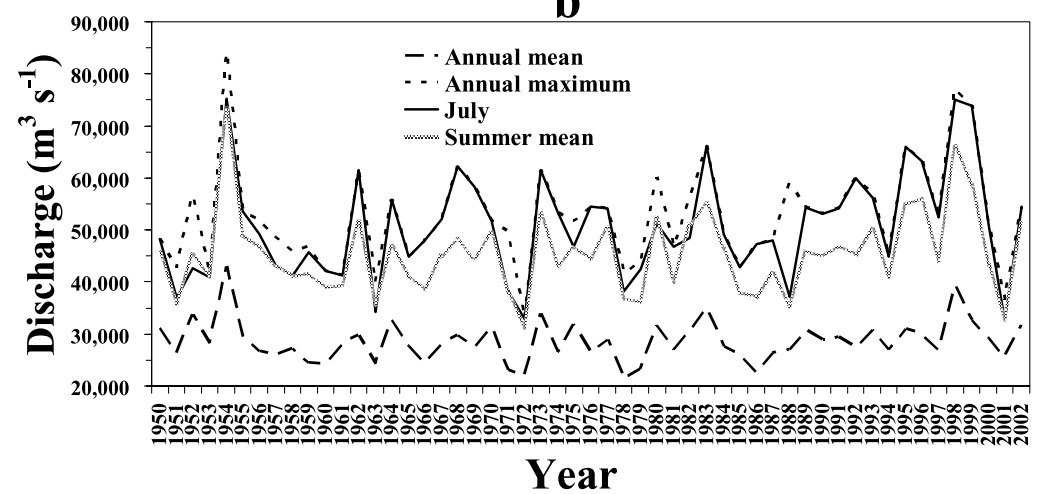

Figure 1. (a) Monthly mean of Changjiang discharge measured at the Datong hydrological gauging station, averaged from 1950 to 2002. (b) Long-term variations of annual mean, annual maximum, summer mean, and July Changjiang discharges measured at the Datong hydrological gauging station from 1950 to 2002 .

resolution, we derived the summer wind magnitude and direction by averaging wind components within the region between $30^{\circ}$ to $32^{\circ} \mathrm{N}$ and $124^{\circ}$ to $126^{\circ} \mathrm{E}$ and over the period from July to September.

\section{Results}

4.1. Interannual, Decadal, and Long-Term Variations in Summer Surface Salinity

[14] Changjiang discharge accounts for about $90 \%$ of the total river discharge into the Yellow, Bohai, and East China Seas. To see the spatial extent and long-term variation of the CDW into the northern ECS, we plotted the zonal distribution of surface salinity from $122^{\circ} 15^{\prime}$ to $130^{\circ} \mathrm{E}$ during the period from 1950 to 2002 (Figure 3b). In general, in the years when the Changjiang discharges were high (Figure $3 a$ ), the outer boundary of the CDW indicated by the 32 isohaline [see Chang and Isobe, 2003] expanded far offshore, exceeding $127^{\circ} \mathrm{E}$, or more than $500 \mathrm{~km}$ east of the Changjiang estuary. This distance agrees with the result reported by Delcroix and Murtugudde [2002].

[15] We plotted the Changjiang discharge against the mean sea surface salinity averaged over the $31^{\circ}$ to $32^{\circ} \mathrm{N}$ latitude range in three different longitude ranges (see Figure 2): $123^{\circ} 30^{\prime}$ to $124^{\circ} 30^{\prime} \mathrm{E}$ (western region), $124^{\circ} 30^{\prime}$ to $125^{\circ} 30^{\prime} \mathrm{E}$ (middle region), and $125^{\circ} 30^{\prime}$ to $126^{\circ} 30^{\prime} \mathrm{E}$ (eastern region). The plots clearly indicated that the inverse relationship between the Changjiang discharge and surface salinity was less significant in the regions further from the Changjiang estuary (Figures 4a, 4b, 4c). The middle and western regions showed a significant relationship between surface salinity and Changjiang discharge, with correlation coefficients of $0.37(p<0.05)$ and $0.42(p<0.05)$, respectively. The high variability of the Changjiang plume path, which was influenced by the Taiwan Warm Current and wind-forced Ekman transport, also seemed likely to play a role in determining the summer surface salinity variation [see Chang and Isobe, 2003].

[16] The mean wind field during the period from 1950 to 2002 period was largely characterized by strong southerly and southeasterly winds. The highest magnitude, $3.87 \mathrm{~m} \mathrm{~s}^{-1}$, was observed in 1951, while the lowest, $0.425 \mathrm{~m} \mathrm{~s}^{-1}$, was observed in 2002 (Figure 3c). Many periods were also characterized by moderate and strong easterly winds, and by weak northerly winds.

[17] In 1954, when the Changjiang discharge was the maximum observed, salinity was relatively high in the

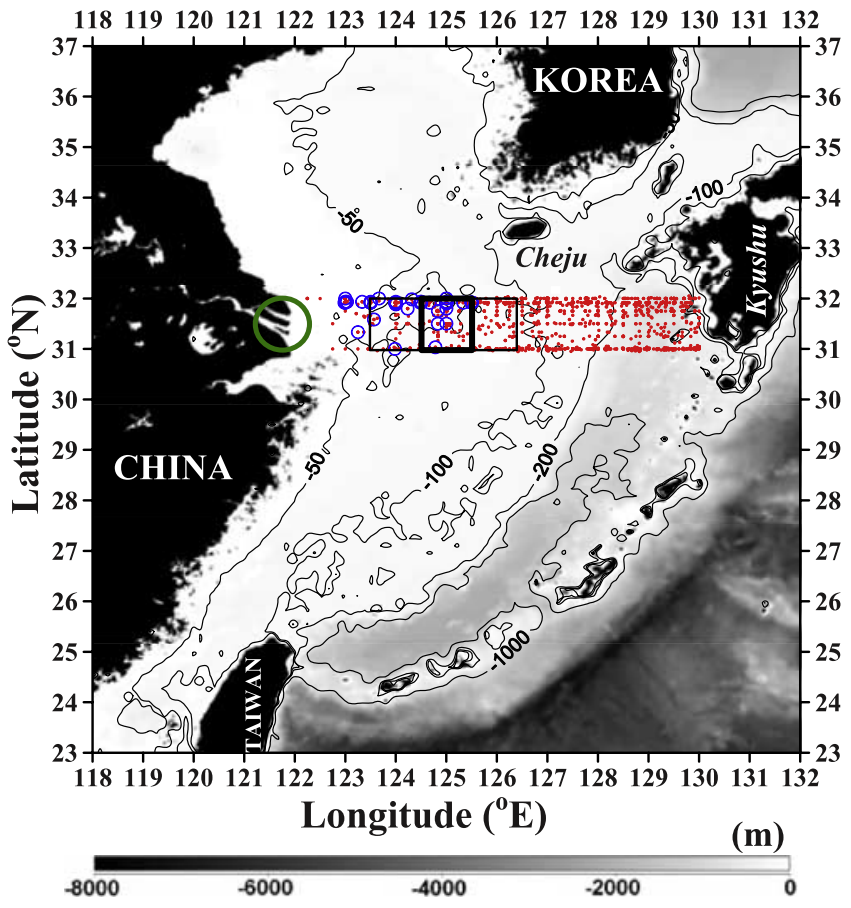

Figure 2. Map of the ECS, showing sampling stations for summer surface salinity (red dots) and DIN (blue circles) data used in this study. The sampling region was from $31^{\circ}$ to $32^{\circ} \mathrm{N}$ and $122^{\circ} 15^{\prime}$ to $130^{\circ} \mathrm{E}$. The three squares indicate the western $\left(123^{\circ} 30^{\prime}-124^{\circ} 30^{\prime} \mathrm{E}\right)$, middle $\left(124^{\circ} 30^{\prime}-\right.$ $125^{\circ} 30^{\prime} \mathrm{E}$ ) and eastern $\left(125^{\circ} 30^{\prime}-126^{\circ} 30^{\prime} \mathrm{E}\right)$ regions (see text). The salinity data within these three squares were used to study long-term variations, with a special emphasis on the middle region (bold square). The green open circle and black areas represent the Changjiang estuary and land, respectively. The bathymetry scale bar and 50, 100, and $200 \mathrm{~m}$ isobaths are also shown. The labels with capital and italic letters indicate the names of countries and islands, respectively. 
$\mathbf{a}$

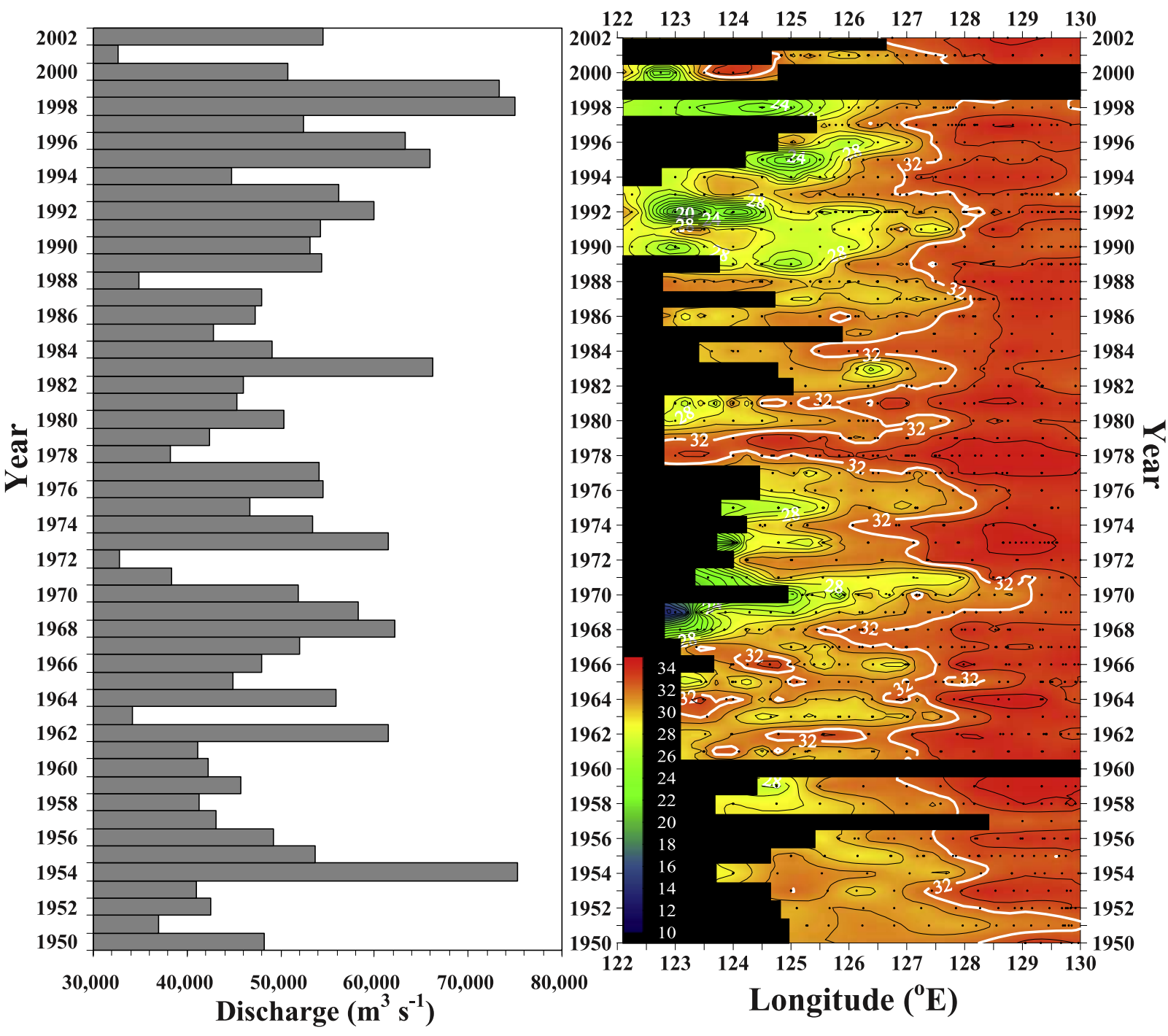

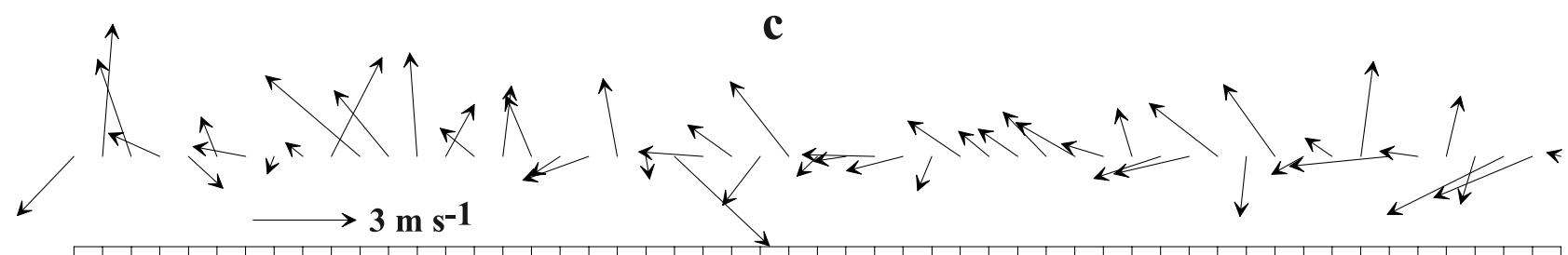

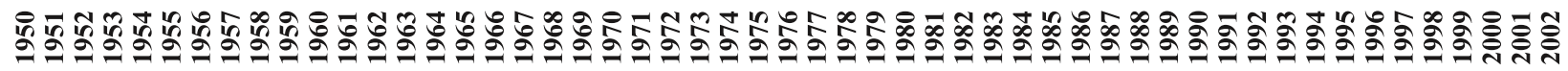
Year

Figure 3. (a) Long-term variation of the summer Changjiang discharge (1950-2002) measured at Datong hydrological gauging station. (b) Long-term and zonal $\left(122^{\circ} 15^{\prime}-130^{\circ} \mathrm{E}\right)$ variations of summer surface salinity (1950-2002). The black bars and white contour indicate no data and the outer boundary of the 32 isohaline, respectively. (c) Variation of the mean summer wind field from 1950 to 2002. The sea surface salinity was averaged from July to September over the 31 to $32^{\circ} \mathrm{N}$ latitude range. The mean summer wind field was derived by averaging wind components from July to September within the region of $30^{\circ}$ to $32^{\circ} \mathrm{N}$ and $124^{\circ}$ to $126^{\circ} \mathrm{E}$. 

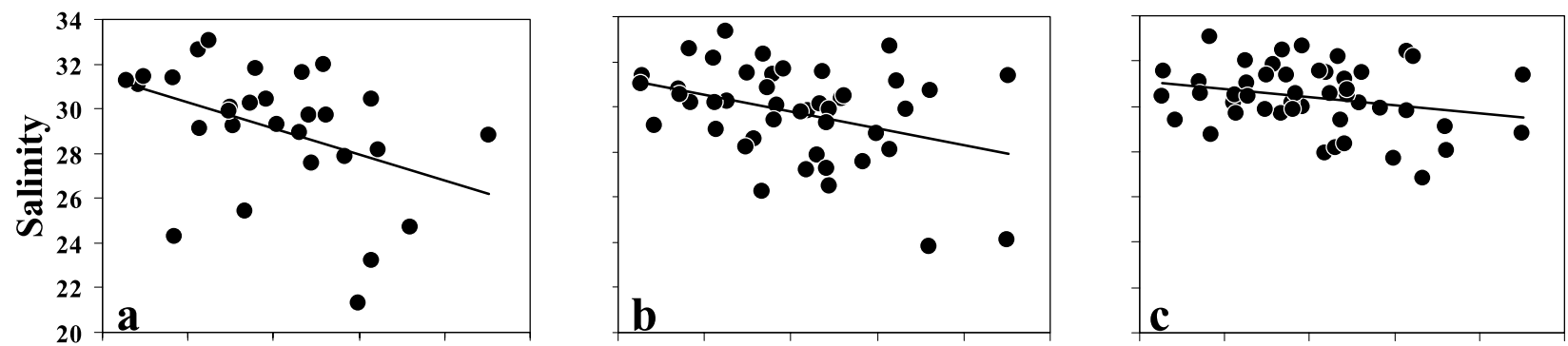

$\begin{array}{lllllllllllllllllll}30,000 & 40,000 & 50,000 & 60,000 & 70,000 & 80,000 & 30,000 & 40,000 & 50,000 & 60,000 & 70,000 & 80,000 & 30,000 & 40,000 & 50,000 & 60,000 & 70,000 & 80,000\end{array}$ Discharge $\left(\mathrm{m}^{3} \mathrm{~s}^{-1}\right)$

Discharge $\left(\mathrm{m}^{3} \mathrm{~s}^{-1}\right)$

Discharge $\left(\mathrm{m}^{3} \mathrm{~s}^{-1}\right)$
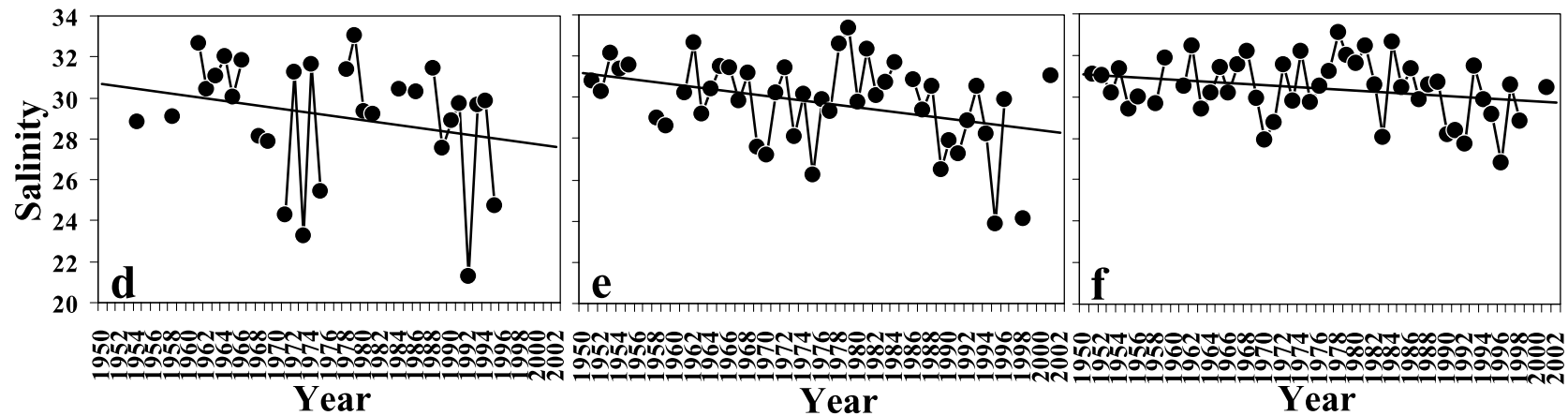

Figure 4. $(a-c)$ Scatter plots of summer surface salinity against Changjiang discharge in the western, middle, and eastern regions, respectively, as depicted by the three squares in Figure 2. (d-f) Long-term variations of summer sea surface salinity in the western, middle, and eastern regions, respectively. The solid lines indicate the linear least-squares fits to the data.

northern ECS. The extension of the 32 isohaline in 1954 did not exceed $128^{\circ} 30^{\prime} \mathrm{E}$. This can be compared to the 32 isohaline in 1951 , which reached $130^{\circ} \mathrm{E}$, even though the 1951 discharge was remarkably low (Figures 3a and 3b). The summer mean wind speed in 1951 was the highest $\left(3.87 \mathrm{~m} \mathrm{~s}^{-1}\right)$ in the investigated period, with the wind blowing in a southerly direction (Figure $3 \mathrm{c}$ ). Because the southerly wind-forced eastward Ekman transport plays an important role in the CDW eastward extension [Chang and Isobe, 2003], it seemed likely that in summer 1951, the CDW was transported farther eastward by this mechanism. In 1954, the wind field was of moderate magnitude $\left(1.37 \mathrm{~m} \mathrm{~s}^{-1}\right)$ and blew northwesterly, causing southwestward Ekman transport that might have constrained the expansion of the CDW to some degree. Another interesting case was observed in 1968, when there was remarkably high Changjiang discharge, but rather high salinity in the northern ECS, and no tongue-like eastward extension of the 32 isohaline. The 32 isohaline probably retreated in this case because the easterly wind forced the withdrawal of freshwater from the shelf [see Chao, 1988].

[18] Another phenomenon was observed in 1962 and 1963. A remarkably high Changiiang discharge occurred in 1962, but the surface salinity decreased only slightly, in a very limited region near the shore. There was no tongue-like eastward extension of low-salinity water, even though a southerly wind prevailed. In contrast, the elongated lowsalinity region from $123.5^{\circ}$ to $127^{\circ} \mathrm{E}$ was obvious in 1963 , when the Changjiang discharge was very low. The same phenomenon of high (low) salinity in the onshore (offshore) region was also obvious in 1991. This salinity variation was probably caused by high variability of the path of the
Changjiang plume, which rotates anticyclonically east of $122.5^{\circ} 30^{\prime} \mathrm{E}$ and turns northeastward under the influence of the Taiwan Warm Current [Chen et al., 2003; Lee and Chao, 2003].

[19] Despite the high interannual variability, sea surface salinity in the three regions of the northern ECS showed a long-term decrease (Figures 4d, 4e, 4f). The closer the region was to the Changjiang estuary, the greater the decrease, indicating a greater susceptibility to long-term variation in the Changjiang discharge. To allow a thorough discussion of the long-term variation of surface salinity in relation to the Changjiang discharge, and other factors such as wind and precipitation, we focused on the middle region of the northern ECS $\left(124^{\circ} 30^{\prime}-125^{\circ} 30^{\prime} \mathrm{E}\right.$, hereafter referred to as the northern ECS). We considered this region suitable for investigating the long-term variation of surface salinity because it had more complete time-series data than the western region, with a more obvious decreasing trend and higher significant correlation with the Changjiang discharge than the eastern region.

[20] From 1951 to 2001, summer sea surface salinity in the northern ECS decreased significantly at a rate of $-0.06 \mathrm{yr}^{-1}$ (Kendall's rank coefficient $[\tau]=-0.222, p<0.05$ ). It ranged from 23.83 in 1995 to 33.34 in 1979 , with an average of 29.80 (Figure 5a). In contrast, the Changiiang discharge measured at Datong hydrological gauging station from 1950 to 2002 increased significantly (Kendall's rank coefficient $[\tau]=0.212, p<0.05$ ) at a rate of $180.85 \mathrm{~m}^{3} \mathrm{~s}^{-1} \mathrm{yr}^{-1}$ (Figure 5a). The discharge ranged from $32,700 \mathrm{~m}^{3} \mathrm{~s}^{-1}$ in 2001 to $75,200 \mathrm{~m}^{3} \mathrm{~s}^{-1}$ in 1954 , with an average value of $50,409 \mathrm{~m}^{3} \mathrm{~s}^{-1}$. 


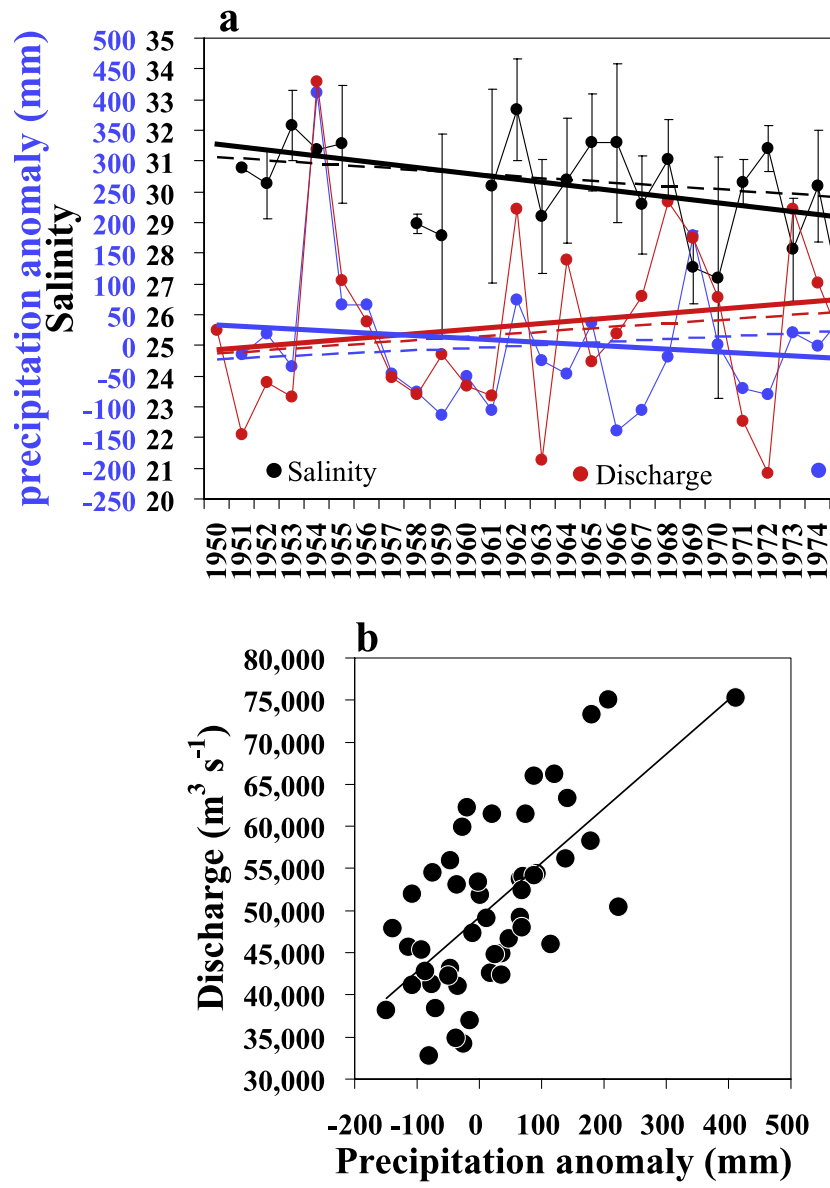

80,000
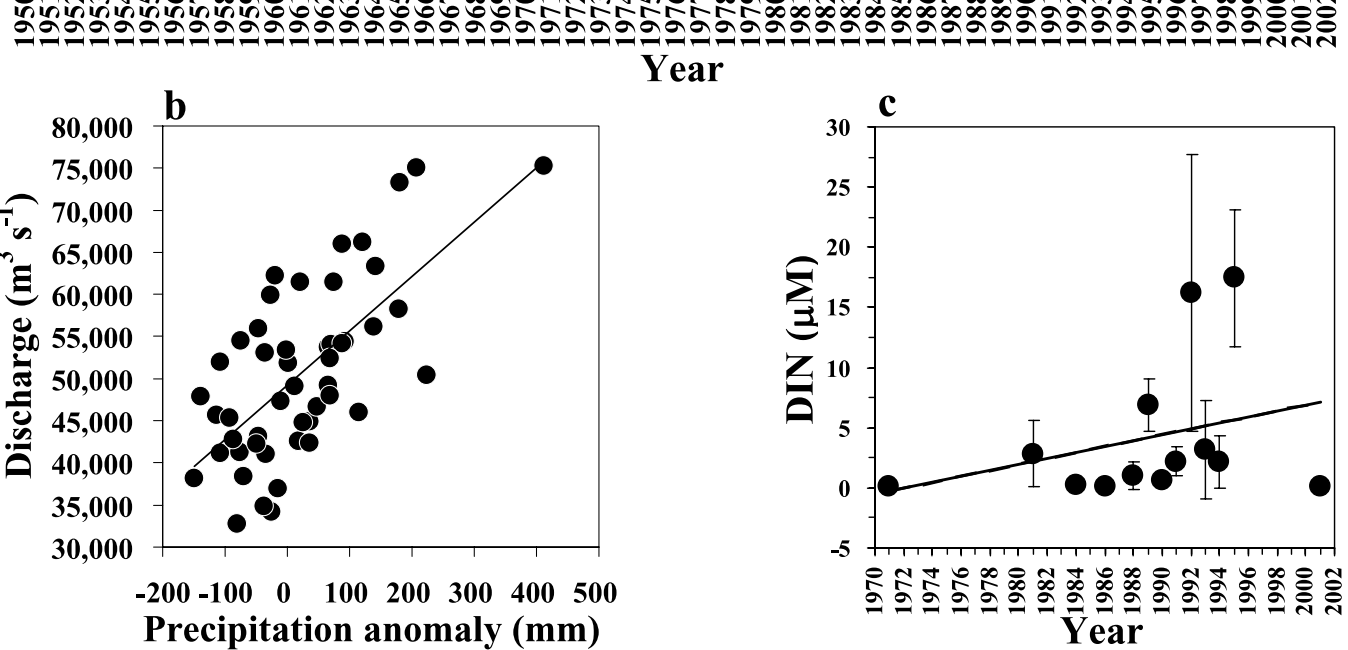

Figure 5. (a) Long-term variations of summer surface salinity in the northern ECS and Changjiang discharge measured at the Datong hydrological gauging station. The dashed lines represent the long-term trends. The precipitation anomaly and long-term trend over the Changjiang valley redrawn from Gong and Ho [2002] are also plotted. The black, red, and blue solid lines represent trends for salinity, discharge, and precipitation anomaly, respectively, within two periods (1950-1977 and 1978-2002, see text). (b) Plot of summer Changjiang discharge against summer precipitation anomaly over the Changjiang valley with a linear least-squares fit. The precipitation anomaly data were extracted from (a). (c) Temporal variation of the summer DIN in the northern ECS during the period from 1971 to 2001. The bars for salinity and DIN in (a) and (c), respectively, indicate the standard deviation.

[21] While the interannual variation of Changjiang discharge varied inversely with the surface salinity, it varied closely with the precipitation anomaly over the Changjiang valley (Figure 5a), with an increase rate of $1.88 \mathrm{~mm} \mathrm{yr}^{-1}$ (Kendall's rank coefficient $[\tau]=0.247, p<0.05$ ). Highvolume Changjiang discharges, such as those in 1954, 1973, 1983 , and 1998, occurred during or immediately following El Niño events which are directly link to rainfall [Shankman et al., 2006]. Indeed, the Changjiang discharge correlated significantly with the precipitation anomaly over Changjiang valley $(\mathrm{r}=0.67, \mathrm{n}=49, p<0.001$, Figure $5 \mathrm{~b})$.

[22] The summer sea surface salinity also varied decadally. During the period from 1978 to 1988, in particular, surface salinity deviated positively from its long-term trend (Figure 5a). Surface salinity increased abruptly from 29.31 in 1977 to 32.54 in 1978 , reaching a value of 33.34 in 1979 (the highest measured during the period of study). The western and eastern regions, which were more influenced by the CDW and Kuroshio water, respectively, also showed high surface salinity during the same period (Figures $4 \mathrm{~d}$ and 4f). This suggested that the high surface salinity within this period was not a local phenomenon.

\subsection{Interannual, Decadal, and Long-Term Variations in Dissolved Inorganic Nitrogen}

[23] The mean summer DIN increased at a rate of $0.25 \mu \mathrm{M}$ $\mathrm{yr}^{-1}$ from 1971 to 2001 (Figure 5c). It increased from $0.166 \mu \mathrm{M}$ in 1971 to $17.470 \mu \mathrm{M}$ in 1995 , with high concentrations more frequently observed after the mid1980s. The high value of DIN in 1995 was concurrent with the lowest salinity value, which seemed to be a result of the relatively high Changjiang discharge in 1995 (Figures 5a and $5 \mathrm{c}$ ). The DIN in summer 2001 was remarkably low, which seemed to be due to the decrease in Changjiang discharge.

[24] A clear inverse relationship between DIN and surface salinity emerged $(\mathrm{r}=0.79, \mathrm{n}=61, p<0.001$, Figure 6a). The relationship between DIN and surface salinity also varied decadally. Separating the data into three periods of 1981 to 1986,1988 to 1994 , and 1995 to 2001, besides 

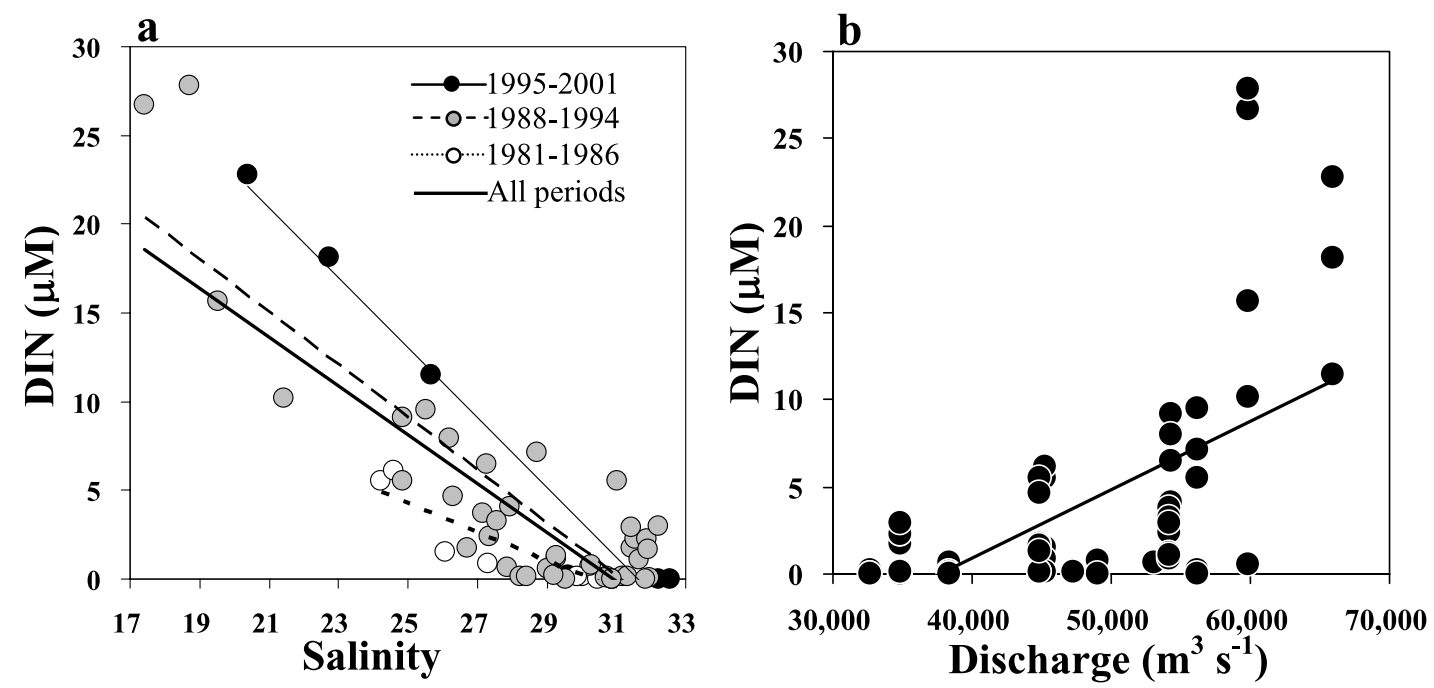

Figure 6. (a) Relationship between summer surface salinity and DIN in the study region. The lines are linear least-squares fits to data for four different periods. (b) Scatter plot of DIN against Changjiang discharge. The solid line indicates the linear least-squares fit to the data.

strong inverse relationships, we also found that the slope of relationship increased with decade. This indicated that at the same salinity levels, the northern ECS surface water had higher DIN in the more recent decade (Figure 6a).

[25] The significant relationship between sea surface salinity and DIN suggested that surface salinity in the northern ECS could indicate the amount of DIN discharged from the Changjiang, as well as the freshwater volume transport from the Changjiang. In fact, the DIN was strongly influenced by the Changjiang discharge, as evidenced by their significant relationship $(\mathrm{r}=0.59, \mathrm{n}=61, p<0.0001$, Figure 6b).

[26] The excess DIN also increased significantly with Changjiang discharges $(\mathrm{r}=0.59, \mathrm{n}=55, p<0.0001$, Figure 7a). As with the long-term DIN variation, high excess DIN was observed more frequently after the late 1980s. We could not compute the excess DIN before the 1980s because no $\mathrm{PO}_{4}-\mathrm{P}$ data were available (Figures $7 \mathrm{~b}$ and $7 \mathrm{c})$.
[27] Human activities over the past few decades might have played a role in determining the observed long-term variations in sea surface salinity and DIN. The ECS was also subject to environmental changes due to climatic warming and the Pacific Decadal Oscillation (PDO) regime shift. The probable connections between the observed longterm variations in surface salinity and DIN, and anthropogenic or natural perturbations, are discussed in the next section, along with the relevance of this work to current environmental problems.

\section{Discussion}

5.1. Probable Causes of the Interannual and Decadal Variations in Summer Surface Salinity

[28] As we described briefly in section 4.1, summer surface salinity in the northern ECS showed a significant long-term decreasing trend, and considerable interannual and decadal variations (Figures 3-5). Although the
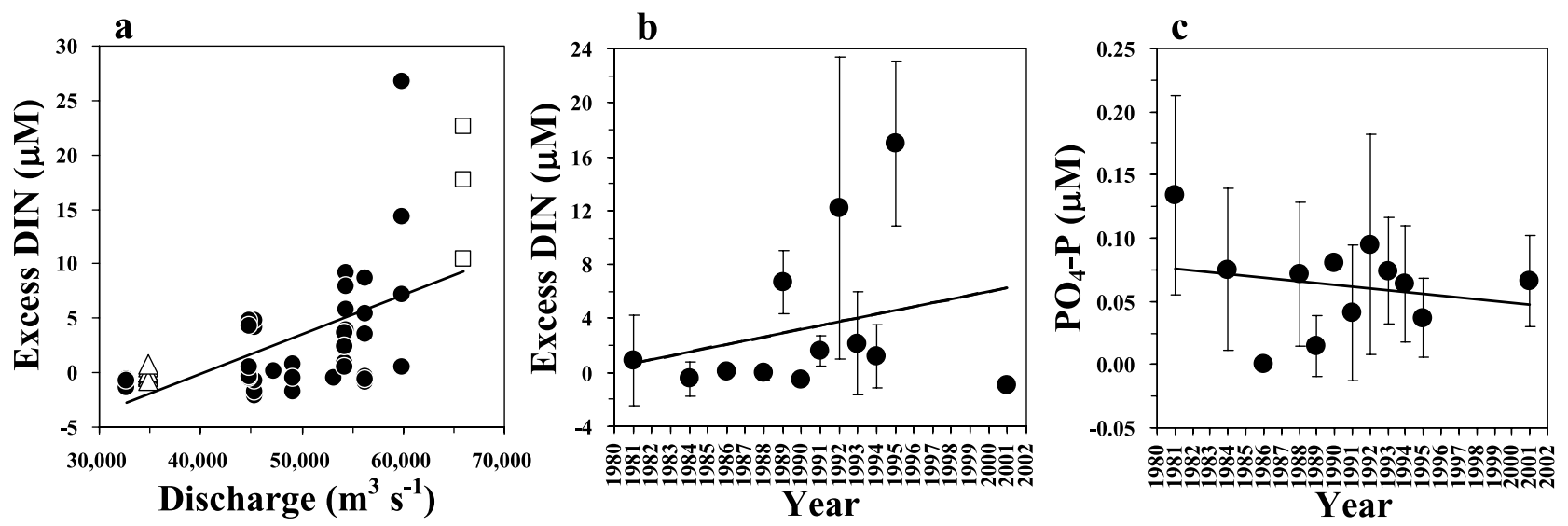

Figure 7. (a) Scatter plot of excess DIN against Changjiang discharge with the linear least-squares fit. The open triangle and squares indicate data from 1988 and 1995, respectively. (b and c) Long-term variations of excess $\mathrm{DIN}$ and $\mathrm{PO}_{4}-\mathrm{P}$, respectively, with long-term trends (solid lines) and standard deviations (bars) included. 

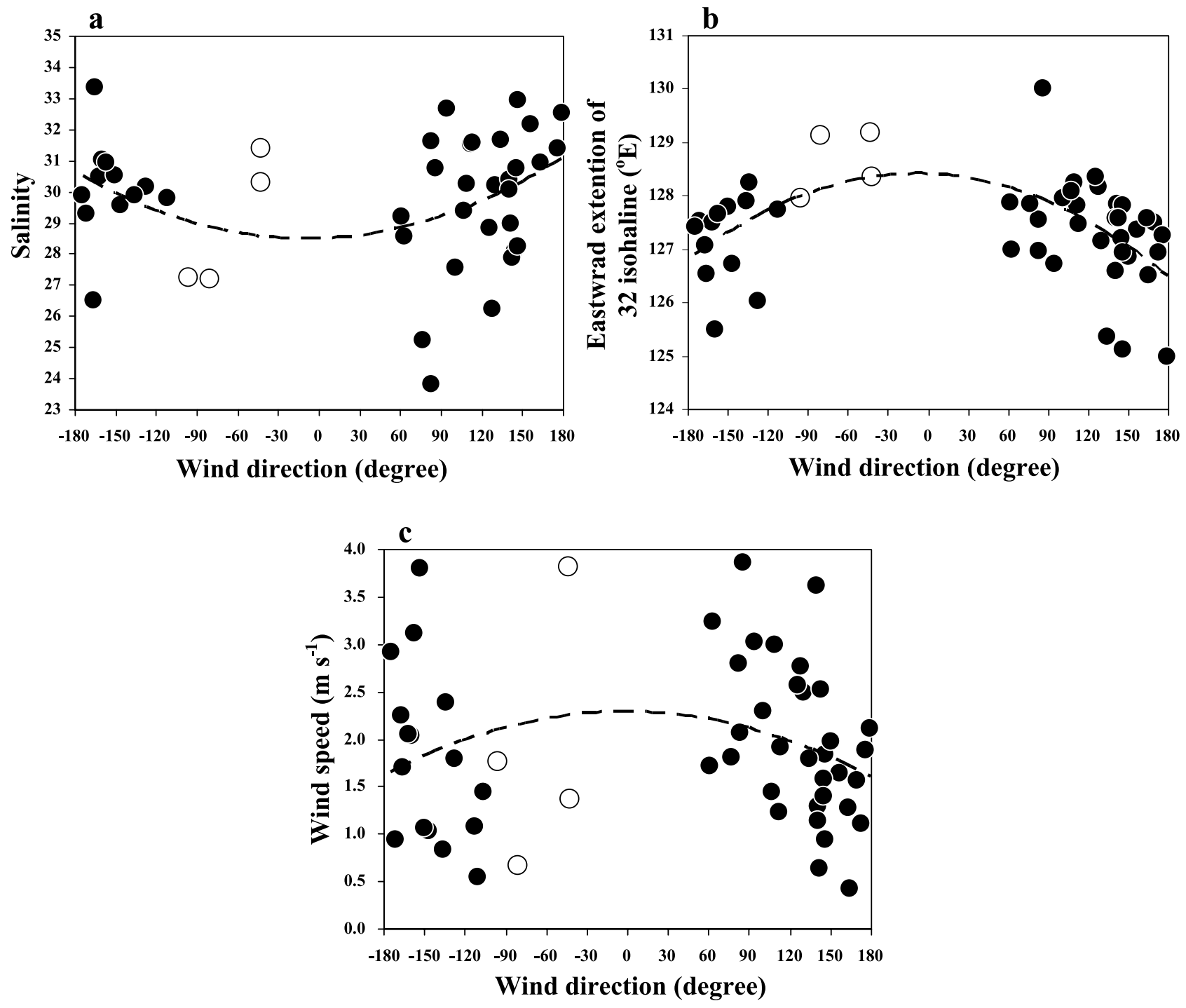

Figure 8. Scatter plots showing the relationships between (a) summer surface salinity, (b) the eastward extension of the 32 isohaline, and (c) wind magnitude, against wind direction, during the investigated period. The dashed curve indicates a second-order polynomial fit. The $x$-axes at $90,-90,0$, and 180 $(-180)$ degrees indicate southerly, northerly, westerly, and easterly wind, respectively. The data represented by open circles show the large eastward extension, which seemed to be caused by the strong zonal wind component (see text and Figure 9c).

Changjiang discharge appeared to be the main controlling factor, the wind field, Taiwan Warm Current, and Kuroshio Current probably also had non-negligible effects [see also Chang and Isobe, 2003; Bang and Lie, 1999; Lee and Chao, 2003].

[29] Because of the complexity of surface circulations in the northern ECS, the variations in summer surface salinity and low-salinity water mass extension in the northern ECS could not always be explained by the Changjiang discharge and/or the wind field, as the influences of the Taiwan Warm and Kuroshio Currents are also of sufficient strength.

[30] In general, when a strong southerly wind prevailed (Figure 8c), surface salinity in the northern ECS tended to be low (Figure 8a), and the 32 isohaline expanded eastward (Figure 8b). This indicated that the CDW, and hence a low surface salinity water mass, were transported eastward by southerly wind-driven Ekman transport. An increase in the meridional wind component caused the 32 isohaline to move eastward ( $r=0.47, p<0.05$; Figure 9a), lowering surface salinity in the northern ECS (Figure 9b). This confirmed the strong dependency of the offshore river plume flow on southerly wind-driven Ekman transport, as described by Chao [1988] and Chang and Isobe [2003].

[31] Even when a northerly wind prevailed, salinity in the northern ECS still decreased, and the 32 isohaline still expanded eastward. This was most likely because the northerly wind was weak (Figure 8c), and thus the Ekman transport might not have been strong enough to constrain the eastward flow of CDW during the high Changjiang discharge season. The eastward extension of the 32 isohaline indicated by four data in Figure $8 \mathrm{~b}$ with negative meridional wind components (Figure 9a) seemed to be 

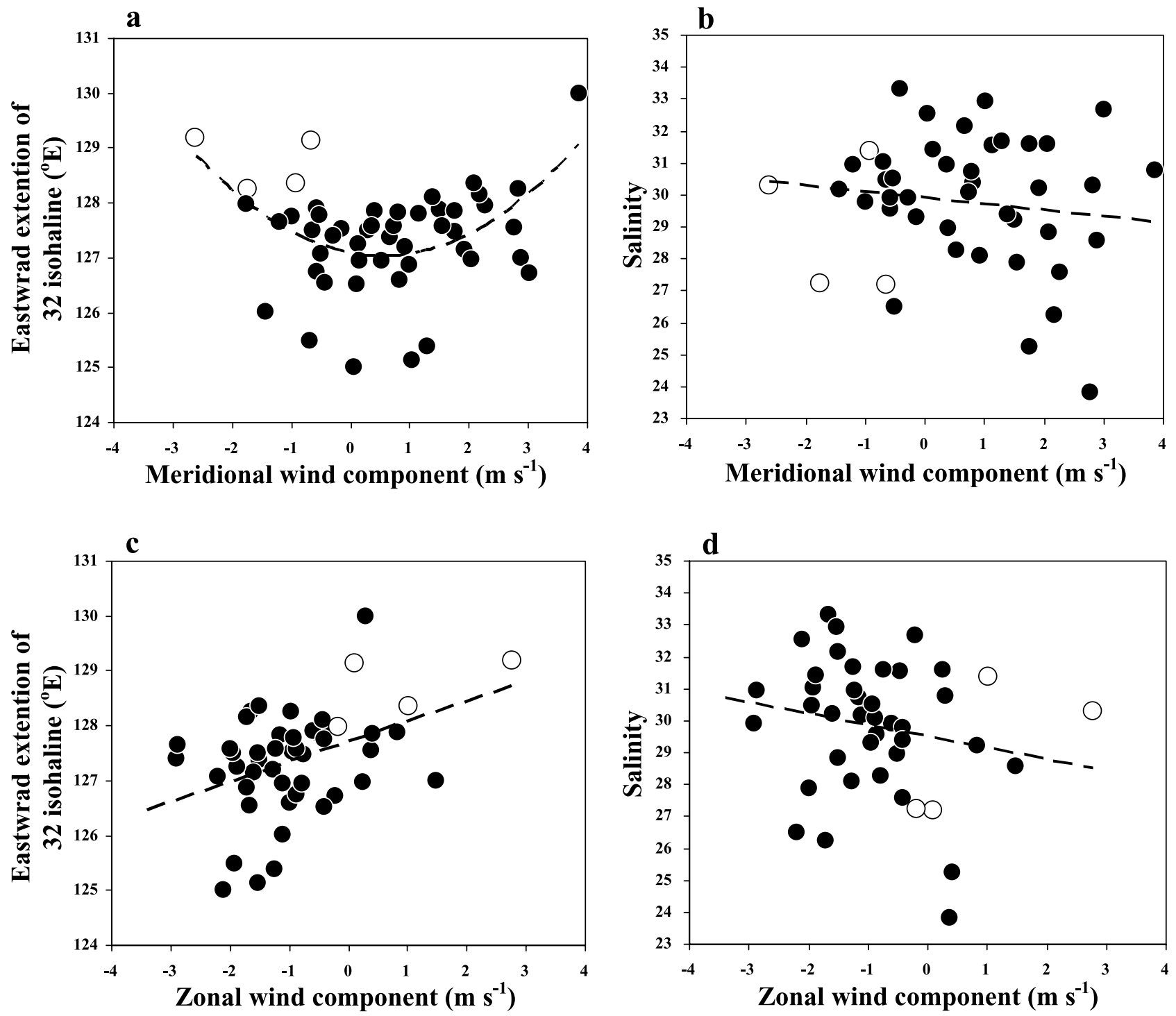

Figure 9. Scatter plots showing the relationships between (a) the 32 isohaline eastward extension, (b) salinity and the meridional wind component, and between (c) the 32 isohaline eastward extension, (d) salinity and the zonal wind component. Positive $(+)$ and negative $(-)$ signs of meridional wind axis in (a) and (b) denote southerly and northerly wind components, respectively. Positive (+) and negative (-) signs of zonal wind axis in (c) and (d) denote westerly and easterly wind components, respectively. Dashed curve in (a) and dashed lines in (b), (c), (d) are, respectively, polynomial and linear fits to the data.

more likely because of the strong zonal wind components (Figure 9c).

[32] When the wind field became easterly, surface salinity in the northern ECS tended to increase, and the eastward extension of the 32 isohaline tended to retreat (Figures $8 \mathrm{a}$ and 8b). As described by Chao [1988], an easterly wind forced the withdrawal of the river plume from the shelf. When a westerly wind prevailed, salinity tended to decrease, and the 32 isohaline moved eastward. In addition, a significant positive correlation emerged between the 32 isohaline eastward extension and zonal wind component $(r=0.44, p<0.05$; Figure $9 \mathrm{c})$. Salinity tended to decrease with the increase in zonal wind component (Figure 9d), indicating that salinity in the northern ECS and the low-salinity offshore extension were also influenced by westerly wind, as it increased the freshwater export onto the shelf [see Chao, 1988].

[33] The surface salinity also varied on a decadal time scale. From 1978 to 1988 , surface salinity was high, deviating from its long-term trend even though the Changjiang discharge anomaly did not change significantly (Figure 10). It has been reported that transport of the Kuroshio Current in the ECS increased in 1976 because of the 1976/1977 PDO regime shift [Zhang and Gong, 2005]. High Kuroshio Current transport lasted until the late 1980 s, concurrent with the end of the warm PDO regime [Figure 10, Hare and Mantua, 2000]. This shift in the Kuroshio Current allowed more saline water to intrude into the northern ECS, and even into the Yellow Sea [Rebstock and Kang, 2003]. Therefore the shift might have been responsible for a high surface salinity tendency in the 


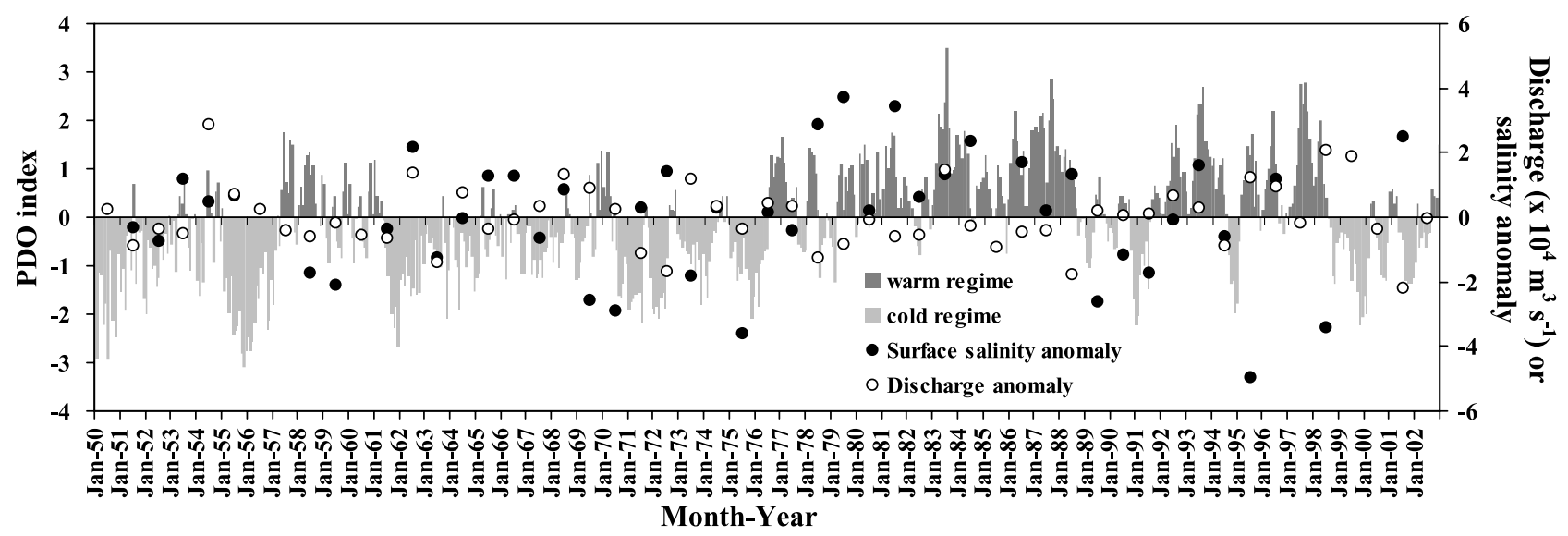

Figure 10. Long-term anomalies of summer surface salinity and summer Changjiang discharge (after removing their long-term trends) superimposed on the PDO index.

northern ECS from 1978 to the late 1980s. Interestingly, the average wind field in the period 1976 to 1989 was generally easterly. Whether the northward Ekman transport forced by this easterly wind intensified the Kuroshio Current is a question for future investigation.

\subsection{Probable Causes of the Long-Term Variation in Summer Surface Salinity}

[34] Regardless of the decadal and interannual variations of summer surface salinity in the northern ECS, it clearly showed an overall decreasing trend from 1951 to 2001. In contrast, both the Changjiang discharge and precipitation anomaly over the Changjiang valley increased in this period. However the significant long-term decreasing (increasing) trend of surface salinity (discharge and precipitation) seemed to be more caused by these quantities after the late 1970 s.

[35] There was a notable regime shift in precipitation over the Changjiang valley in the late 1970s. It was relatively low before 1979 and increased steadily after that year [Gong and Ho, 2002]. As a result, the increasing trend in the Changjiang discharge was also greater after this time (Figure 5a). The increase rates in precipitation anomaly and Changjiang discharge from 1978 to 2002 were $6.53 \mathrm{~mm} \mathrm{yr}^{-1}$ and $542.90 \mathrm{~m}^{3} \mathrm{~s}^{-1} \mathrm{yr}^{-1}$, respectively (Figure 5a). These increase rates were greater than the overall rates from 1950 to 2002, which were $1.88 \mathrm{~mm} \mathrm{yr}^{-1}$ and $180.85 \mathrm{~m}^{3} \mathrm{~s}^{-1} \mathrm{yr}^{-1}$, respectively. The high salinity occurred from 1978 to 1988 associated with an increase in the Kuroshio Current transport made the decrease rate in summer surface salinity in the northern ECS within the period from 1978 to $2001\left(-0.23 \mathrm{yr}^{-1}\right.$, Figure 5a) was greater than the overall rate of $-0.06 \mathrm{yr}^{-1}$.

[36] From 1950 to 1977 , even though precipitation anomaly tended to decrease at the rate of $-2.00 \mathrm{~mm} \mathrm{yr}^{-1}$ (Figure 5a), Changjiang discharge still showed an increasing trend with the rate of $189.87 \mathrm{~m}^{3} \mathrm{~s}^{-1} \mathrm{yr}^{-1}$, slightly higher than the overall rate of $180.85 \mathrm{~m}^{3} \mathrm{~s}^{-1} \mathrm{yr}^{-1}$. Within the same period, surface salinity decreased at the rate of $-0.09 \mathrm{yr}^{-1}$ (Figure 5a), implying that its long-term decreasing trend was indeed because of the long-term increasing trend in Changjiang discharge. However, with the decrease in pre- cipitation before 1979 over the Changjiang valley east of $107^{\circ} \mathrm{E}$ [see Gong and Ho, 2002], there must have been another source of freshwater to maintain the steady increase (decrease) trend of discharge (salinity).

[37] Climatic warming has increased the air temperature in western China, the region west of $105^{\circ} \mathrm{E}$ [see Ding et al., 2006 ] by $0.2^{\circ} \mathrm{C}$ per decade since 1951 , with 1998 was the warmest year so far. This increase in air temperature caused precipitation in western China to increase by 5 to $10 \%$ per decade. It has also caused $>80 \%$ of glaciers to retreat, increasing glacier runoff as a result [Ding et al., 2006]. These two effects likely increased the Changjiang discharge during the period of investigation. The highest Changjiang discharge in 1998 since the highest in 1954 generally considered associated with El Niño event [e.g., Shankman et al., 2006], to some degree might also be associated with the warmest climate in western China. Therefore the most likely sources for the Changjiang discharge increase were meltwater from glaciers and precipitation increases in western China. The IPCC [1998] also noted that increases in glacial melt due to global warming led to an increase in summer discharge flows in some river systems.

[38] We therefore concluded that the long-term decrease in summer surface salinity in the northern ECS was indeed caused by a long-term increase in Changjiang discharge, which in turn was likely caused by the increase in precipitation and glacier runoff from western China. Precipitation over the northern ECS probably contributed negligibly to the long-term variation in surface salinity [Delcroix and Murtugudde, 2002], as the freshwater flux due to precipitation over this region is nearly balanced by evaporation [Chen et al., 1994].

\subsection{Probable Causes of the Long-Term Variation in Summer Surface Dissolved Inorganic Nitrogen Concentration}

[39] The long-term increase in DIN observed in the northern ECS matched the changes observed in regions closer to the coast [e.g., Wang, 2006; Chai et al., 2006; Shuiwang et al., 2000]. However concentration was lower in the northern ECS because of the dilution by shelf water. This long-term increase in DIN could have been because of 

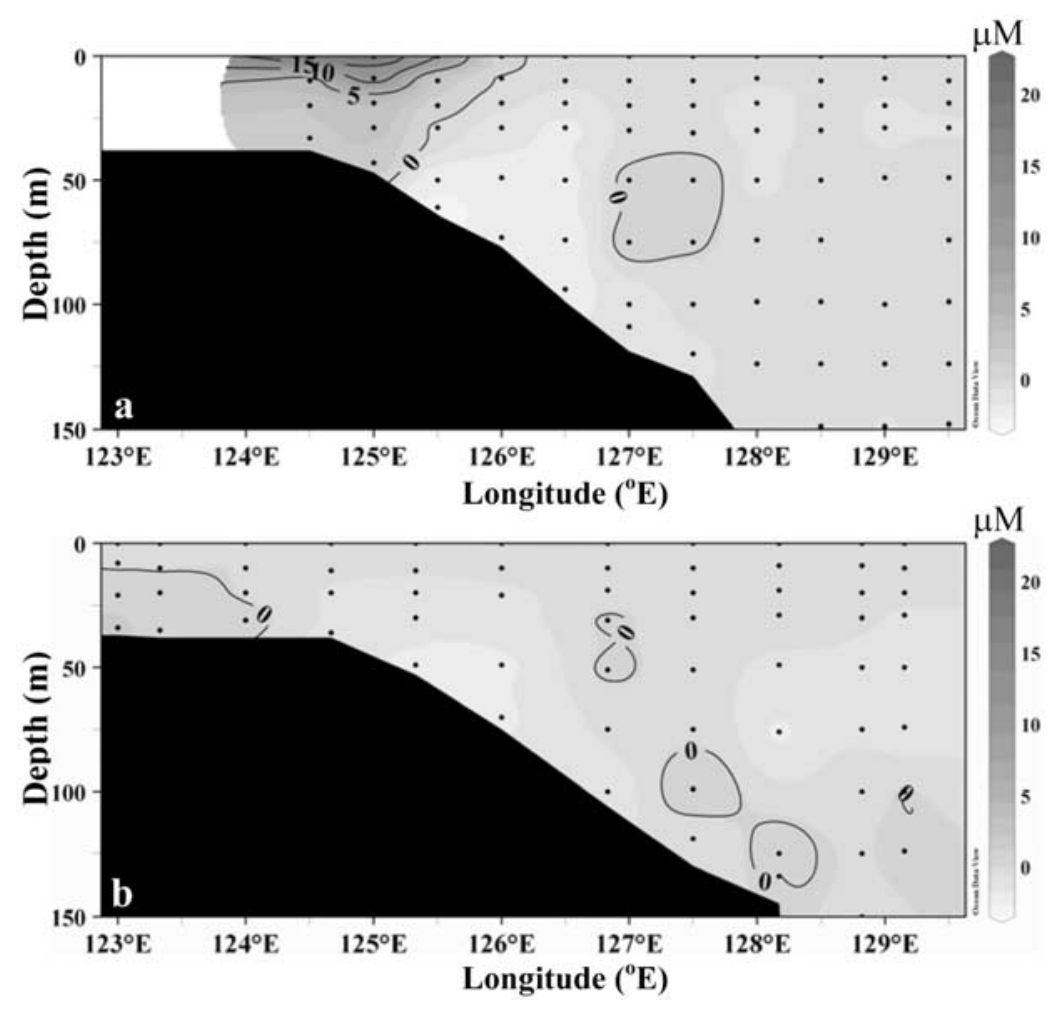

Figure 11. (a), (b) Spatial variation of summer excess DIN along $31^{\circ} 55^{\prime} \mathrm{N}$ for 1995 and 1988 , with longitude ranges from $124^{\circ} 30^{\prime} \mathrm{E}$ to $129^{\circ} 30^{\prime} \mathrm{E}$ and $123^{\circ}$ to $129^{\circ} 09^{\prime} \mathrm{E}$, respectively. The black dots indicate the discrete sampling depths. White area in (a) indicates no data were available.

the drastic increase in nitrogen fertilizer use in China since the 1980s [e.g., Wang et al., 1996; Shuiwang et al., 2000].

[40] Although the long-term increase in DIN $(0.25 \mu \mathrm{M}$ $\mathrm{yr}^{-1}$ ) was most likely because of high DIN in $1990 \mathrm{~s}$ (Figure 5c), there was still an increasing trend $(0.17 \mu \mathrm{M}$ $\mathrm{yr}^{-1}$ ) within the period from 1971 to 1989 . If a very low DIN measurement in 2001 was excluded, DIN in 1990s had the increase trend of $2.03 \mu \mathrm{M} \mathrm{yr}^{-1}$. In any case, the increase in DIN from 1990 to 1995 was greater than that from 1971 to 1989 , quite possibly because of the increase in nitrogen fertilizer use in China.

[41] We compared the spatial distributions of excess DIN along $31^{\circ} 55^{\prime} \mathrm{N}$ in 1988 and 1995 . In 1988 , we found that there was no excess DIN at $123^{\circ} \mathrm{E}$ (about $100 \mathrm{~km}$ east of the Changjiang estuary). However, in 1995, excess DIN reached $126^{\circ} \mathrm{E}$ (about $400 \mathrm{~km}$ east of the Changjiang estuary), as shown in Figure 11. The large spread of excess DIN in 1995 might have been due to the relatively high DIN (17.47 $\mu \mathrm{M}$, compared to $0.98 \mu \mathrm{M}$ in 1988) and high Changjiang discharge $\left(66,000 \mathrm{~m}^{3} \mathrm{~s}^{-1}\right.$, compared to $34,900 \mathrm{~m}^{3} \mathrm{~s}^{-1}$ in 1988).

[42] Because the Changjiang discharge was correlated significantly with both DIN and excess DIN (Figures 6b and $7 \mathrm{a}$ ), and also showed a long-term increase (Figure 5a), it seemed likely that the long-term increases in DIN and excess DIN were because of the Changjiang discharge variation. However, with the long-term increase rate of Changjiang discharge of $180.85 \mathrm{~m}^{3} \mathrm{~s}^{-1} \mathrm{yr}^{-1}$, and increase rate of DIN with Changjiang discharge of $0.0004 \mu \mathrm{M}\left(\mathrm{m}^{3} \mathrm{~s}^{-1}\right)^{-1}$ (derived as the slope of the linear least squares fit in
Figure 6b), long-term increase in Changjiang discharge alone should increase DIN with the rate of $0.07 \mu \mathrm{M} \mathrm{yr}^{-1}$, which was much lower than the observed rate $\left(0.25 \mu \mathrm{M} \mathrm{yr}^{-1}\right)$.' Hence it seemed likely that the long-term increases in DIN and excess DIN were also because of the increase in nitrogen fertilizer use in China.

\subsection{Relevance to Recent Environmental Problems}

[43] The long-term DIN increase in the ECS has had ecological impacts. Based on in situ measurement, Chai et al. [2006] reported a long-term increase of phytoplankton biomass (chlorophyll- $a$ ) in the offshore region $\left(122^{\circ} 18^{\prime}-\right.$ $\left.123^{\circ} 18^{\prime} \mathrm{E}, 30^{\circ} 45^{\prime}-32^{\circ} \mathrm{N}\right)$. The overall decadal increase in chlorophyll-a retrieved from satellite observations of ocean color in the western ECS reported by Son et al. [2005] might also have been related to the DIN increase.

[44] Within the period from 1981 to $2001 \mathrm{PO}_{4}-\mathrm{P}$ only slightly decreased at the rate of $-0.001 \mu \mathrm{M} \mathrm{yr}^{-1}$ (Figure 7c), agrees well with the result of Wang [2006] showing a relatively constant $\mathrm{PO}_{4}$-P. Assuming a constant DIN within the period from 1981 to 2001, the increase rate of excess DIN solely associated with the slight decrease in $\mathrm{PO}_{4}-\mathrm{P}$ was only about $0.02 \mu \mathrm{M} \mathrm{yr}^{-1}$. This rate was much lower than the overall increase rate of excess DIN within the same period $\left(0.28 \mu \mathrm{M} \mathrm{yr}^{-1}\right)$ indicating that the long-term increase in excess DIN was largely attributed to the long-term increase in DIN. This long-term increase in excess DIN also indicated that in the last few decades, DIN increased over the level that could be used by phytoplankton. This 
meant that biological production in the northern ECS changed from DIN limiting, to $\mathrm{PO}_{4}-\mathrm{P}$ limiting.

[45] The increase in DIN and excess DIN were also relevant to the increased frequency of red tide outbreaks in the Chinese coastal waters over the last few decades. Since the 1980s, when both DIN and excess DIN increased drastically because of nitrogen fertilizer use, red tides have occurred frequently in the Changjiang estuary and nearby areas, and the spatial extents of red tides have increased with time [see Gao and Song, 2005; Wang, 2006]. About $75 \%$ of the red tide outbreaks observed from 1986 to 1993 occurred over the western inner shelf of the ECS, close to our study region [Hong, 2003].

[46] Furthermore, the long-term increase in excess DIN, combined with the long-term decrease in silicates [see Wang, 2006], was most likely responsible for dramatic shifts in dominant phytoplankton species. Wang [2006] and Chen et al. [2003] found that changes in the chemistry of the Changjiang plume prevented diatoms (Skeletonema costatum) from competing effectively with other algal classes, giving a selective advantage to dinoflagellates (Prorocentrum dentatum, Noctiluca scintillans, and Alexandrium spp.).

\section{Conclusions}

[47] From 1951 to 2001, summer sea surface salinity in the northern ECS varied strongly on interannual and decadal time scales. The summer sea surface water in the northern ECS also freshened dramatically. The interannual variation of summer surface salinity was not only determined by the Changjiang discharge, but also by the regional wind fields and surface circulations. The increase in Kuroshio Current transport associated with the PDO regime shift seemed to be responsible for the high salinity tendency from 1978 to 1988. We attributed the long-term decrease in summer surface salinity to the long-term increase in Changjiang discharge, which was probably caused by an increase in precipitation and glacier runoff in western China.

[48] The long-term increase in DIN appeared to depend on both the changes in Changjiang discharge and the increase in nitrogen fertilizer use in China since the 1980s. The long-term increase in DIN modified the nutrient composition, causing the excess DIN to increase. This result implied that the biological production in the northern ECS changed from DIN limiting, to $\mathrm{PO}_{4}-\mathrm{P}$ limiting.

[49] The long-term increase in DIN also seemed to be relevant to the frequent red tide outbreaks in the ECS. We should pay attention to changes in the northern ECS ecosystem and its connected seas in future decades because the volume of the Changjiang discharge, as well as its physical and chemical properties, may change dramatically because of the continuous anthropogenic perturbations and climate change.

[50] Acknowledgments. The authors would like to thank Professor Zhu for his permission to use the Changjiang discharge data. We also extend our appreciation to Dr. M. Minagawa and Dr. T. Ono for their many useful insights, discussions, and suggestions. We are grateful to two anonymous reviewers, whose constructive comments led to a greatly improved paper. This study was supported by the Global Change project, which was funded by the Ministry of Agriculture-Forest-Fisheries, Japan.
The study was also partially supported by grants from the Japan Society for the Promotion of Science.

\section{References}

Bang, I., and H.-J. Lie (1999), A numerical experiment on the dispersion of the Changjiang river plume, J. Korean Soc. Oceanogr., 34, 873-883.

Bodo, B. A. (2001), Annotations for monthly discharges data for world rivers (excluding former Soviet Union), $85 \mathrm{pp}$. (Available at http://dss. ucar.edu/datasets/ds552.1/docs/)

Chai, C., Z. Yu, X. Song, and X. Cao (2006), The status and characteristic of eutrophication in the Yangtze River (Changjiang) estuary and the adjacent East China Sea, China, Hydrobiologia, 563, doi:10.1007/ s10750-006-0021-7.

Chang, P. H., and A. Isobe (2003), A numerical study on the Changjiang diluted water in the Yellow and East China Seas, J. Geophys. Res., 108(C9), 3299, doi:10.1029/2002JC001749.

Chao, S.-Y. (1988), Wind-driven motion of estuarine plumes, J. Phys. Oceanogr., 18, 1144-1166.

Chen, C., R. C. Beardsley, R. Limeburner, and K. Kim (1994), Comparison of winter and summer hydrographic observations in the Yellow and East China Sea and adjacent Kuroshio during 1986, Cont. Shelf Res., 14, 909-929.

Chen, C., J. Zhu, C. R. Beardsley, and P. J. S. Franks (2003), Physicalbiological sources for dense algal blooms near the Changjiang River, Geophys. Res. Lett., 30(10), 1515, doi:10.1029/2002GL016391.

Delcroix, T., and R. Murtugudde (2002), Sea surface salinity changes in the East China Sea during 1997-2001: Influence of the Yangtze River, J. Geophys. Res., 107(C12), 8008, doi:10.1029/2001JC000893.

Ding, Y., S. Liu, J. Li, and D. Shangguan (2006), The retreat of glaciers in response to recent climate warming in western China, Ann. Glaciol., 43, $97-105$.

Gao, X., and J. Song (2005), Phytoplankton distributions and their relationship with the environment in the Changjiang Estuary, China, Mar. Pollut. Bull., 50, 327-335.

Gong, D.-Y., and C.-H. Ho (2002), Shift in the summer rainfall over the Yangtze River valley in the late 1970s, Geophys. Res. Lett., 29(10), 1436, doi:10.1029/2001GL014523.

Hare, S. R., and N. J. Mantua (2000), Empirical evidence for North Pacific regime shifts in 1977 and 1989, Prog. Oceanogr., 47, 103145.

Hong, J. C. (2003), Ecological study on red tide in the China main estuaries and bays. Part VI. Changiiang Estuary, in China Inshore Red Tide, edited by Y. Z. Qi, pp. 159-178, Science Press, Beijing.

IPCC (1998), The Regional impacts of climate change: An assessment of vulnerability, in Special Report of IPCC Working Group II, edited by R. T. Watson, M. C. Zinyowera, and R. H. Moss, 517 pp., Intergovernmental Panel on Climate Change, Cambridge Univ. Press, Cambridge, UK.

Kawahara, M., S.-I. Uye, K. Ohtsu, and H. Iizumi (2006), Unusual population explosion of the giant jellyfish Nemopilema nomurai (Scyphozoa: Rhizostomeae) in East Asian waters, Mar. Ecol. Prog. Ser., 307, $161-$ 173.

Lee, H.-J., and S.-Y. Chao (2003), A climatological description of circulation in and around the East China Sea, Deep Sea Res., Part II, 50, 1065 1084

Li, M., K. Xu, M. Watanabe, and Z. Chen (2007), Long-term variations in dissolved silicate, nitrogen, and phosphorus flux from the Yangtze River into the East China Sea and impacts on estuarine ecosystem, Estuarine Coastal Shelf Sci., 71, 3-12.

Nof, D. (2001), China's development could lead to bottom water formation in the Japan/East Sea, Bull. Am. Meteorol. Soc., 82, 609-618.

Rebstock, G. A., and Y. S. Kang (2003), A comparison of three marine ecosystems surrounding the Korean peninsula: Response to climate change, Prog. Oceanogr., 59, 357-379.

Senjyu, T., H. Enomoto, T. Matsuno, and S. Matsui (2006), Interannual salinity variations in the Tsushima Strait and its relation to the Changjiang discharge, J. Oceanogr., 62, 681-692.

Shankman, D., B. D. Keim, and J. Song (2006), Flood frequency in China's Poyang Lake region: Trends and teleconnections, Int. J. Clim., 26, 12551266.

Shuiwang, D., Z. Shen, and H. Hongyu (2000), Transport of dissolved inorganic nitrogen from the major rivers to estuaries in China, Nutr. Cycl. Agroecosys., 57, 13-22.

Son, S. H., J. Campbell, M. Dowell, and S. Yoo (2005), Decadal variability in the Yellow and East China Seas as revealed by satellite ocean color data, Indian J. Mar. Sci., 34(4), 418-429.

Wang, B. (2006), Cultural eutrophication in the Changjiang (Yangtze River) plume: History and perspective, Estuarine Coastal Shelf Sci., 69, 471477. 
Wang, Q. B., C. Halbrendt, and S. R. Johnson (1996), Grain production and environmental management in China's fertilizer economy, J. Environ. Manag., 47, 283-296.

Wong, G. T. F., G.-C. Gong, K.-K. Liu, and S.-C. Pai (1998), "Excess nitrate" in the East China Sea, Estuarine Coastal Shelf Sci., 46, 411-418.

Xu, K., J. D. Milliman, Z. Yang, and H. Wang (2006), Yangtze sediment decline partly from Three Gorges Dam, Eos Trans. AGU, 87(19), 185, doi:10.1029/2006EO190001.

Yanagi, T. (2002), Water, salt, phosphorus and nitrogen budgets of the Japan Sea, J. Oceanogr., 58, 797-804.

Yang, Z. S., J. D. Milliman, and M. D. Fitzgerald (1983), Transfer of water and sediment from the Yangtze River to the East China Sea, June 1980 , Can. J. Fish. Aquat. Sci., 40, 72-82.
Zhang, C. I., and Y. Gong (2005), Effect of ocean climate changes on the Korean stock of Pacific saury, Cololabis saira (BREVOORT), J. Oceanogr., 61, 313-325.

J. Ishizaka and H. Nakata, Faculty of Fisheries, Nagasaki University, 1-14 Bunkyo-machi, Nagasaki 852-8521, Japan. (nakata@nagasaki-u.ac.jp; ishizaka@nagasaki-u.ac.jp)

Y. Kiyomoto and K. Okamura, East China Sea Fisheries Oceanography Division, Fisheries Research Agency, Seikai National Fisheries Research Institute, 1551-8 Taira-machi, Nagasaki 851-2213, Japan. (ykiyo@ fra.affrc.go.jp; mrmaro@fra.affrc.go.jp)

Y. Matsuoka, Nagasaki Food Hygiene Association, 3640-3 Kuodago, Nagayo-cho, Nagasaki 851-2127, Japan. (matsuoka-uji@nsek.or.jp)

E. Siswanto, Hydrospheric Atmospheric Research Center, Nagoya University, Furo-cho, Chikusa-ku, Nagoya 464-8601, Japan. (eksis@hyarc. nagoya-u.ac.jp)

K. Tanaka, Japan International Research Center for Agricultural Sciences, 1-1 Owashi, Tsukuba 305-8686, Japan. (katuhi@affrc.go.jp)

J. Zhu, State Key Laboratory of Estuarine and Coastal Research, East China Normal University, North Zhongshan Road 3663, Shanghai 200062, China. (jrzju@sklec.ecnu.edu.cn) 